and technical colleges. Complacency about all things technological has also diverted it from a critical appraisal of the engineering professions, and from the need to pay technologists more money. On the other hand, there has grown up the view that the work of the pure sciences is somehow irrelevant to the progress of technology and the health of British industry. The best that can be said of it is that this opinion is illinformed. Nobody knows enough to know how best to strike a balance between technology and what is now called science, although there is no question that they are in some sense mutually dependent. The best service Mr. Benn could do his Ministry, and the industry it is meant to serve, would be to convince his acolytes that science and technology are really inseparable parts of the same entity.

\section{DATA FOR PHYSICS}

THE Institution of Electrical Engineers is right to ask itself what kind of service Physics Abstracts should provide (see p. 112 of this issue), but there is more at stake than mere modernity. The question of whether the world's principal physics abstracting journal should continue to be published from the United Kingdom is also involved. One difficulty is that Physics Abstracts, like other abstracting journals, is not a paying proposition. Costs keep rising, and more or less in tume with the steadily increasing volume of publications in physics. At the same time, there is a steady pressure for an ever faster service, which means high capital expenditure on data processing equipment and the like. Yet circulation is linked not with the volume of scientific activity, but with the number of laboratories and libraries, and there are obvious limits to the extent to which it can be taxed. These are the principal reasons why subsidies are necessary. In recent years, American sources have generously helped to keep Physics Abstracts on its feet.

More recently, however, there has been a tendency to believe the job could be done more efficiently in the United States. Though the service offered by Physics Abstracts has been steadily improving, and though this is now augmented by the new journal Current Papers in Physics, there is no question that American experience in running abstracting journals far outstrips that in the United Kingdom. Nuclear Science Abstracts and Chemical Abstracts are both masterpieces of the application of technology to the processing of scientific information. From time to time there 1 as actually been talk of letting Nuclear Science Abstrcts grow so as to include the whole of physics, though the prospect of this happening is to some extent restricted by the view of the United States Government that responsibility for nuclear abstracting should belong to some international authority-the International Atomic Energy Agency, for example. In any event, there seems to be an entirely sensible recognition within the community of physicists that an efficient abstracting service must inherently be international. The American Institute of Physics has been particularly keen, in recent years, to help the Institution of Electrical Engineers along by providing timely abstracts of material appearing in its own journals. In a sense, one object of the study on which the Institution of Electrical Engineers has now embarked is to find some way of matching American efficiency with British. With luck, there is no reason why the venture should not succeed, though there are signs that American critics of present arrangements would be more easily satisfied if the Institute of Physics in Britain were more closely concerned in producing Physics Abstracts.

Producing abstracts quickly is, however, only half the battle. Knowing how best to use them is another problem which is harder to resolve. The most obvious difficulty is the most serious, for ordinary people find it hard to accumulate information by ploughing through the abstracting journals. This is why large laboratories provided with efficient information services have taken to distributing extracts from the abstracts to those known to have an interest in them. By all accounts, the system works well. It is certain to be imitated as widely as circumstances and machines permit, and there is no reason why even small laboratories should not be helped with selected abstracts by some central service. But how, then, to browse? Evidently there is a need for ways of letting scientists know something of the contents of a wide selection of the literature, and this is where new types of journals may have an important part to play. In all the circumstances, the Institution of Electrical Engineers should not be too dismayed if its enquiries suggest that there is only a limited future for abstracting journals as at present known. It is more important to provide the kind of service which the professionals need.

\section{NO MORE VISITS}

THE Society for Visiting Scientists has announced that it will in future not collect scientific periodicals and books and that its present collection will be disbanded. This is another step in the slow process by which the Society appears to be being driven out of existence. Ever since it left its cheap-rent premises in old Burlington Street, the Society has found it hard to make ends meet. In its annual report published in December 1965, the Society said that the "news of our financial situation is bleak. We anticipated no substantial increase in membership involving full subscription, in view of the fact that we no longer are able to provide the club amenities we used to offer". In the event the Society has found that covenants signed by a number of companies several years ago have run out simultaneously. Though some support continues, it looks as if the British Council will be the only enduring source of funds.

In spite of the vigorous programme of lectures and discussions arranged for last year, officials of the Society are inclined to be as despondent as these hard facts suggest they should be. The trouble, of course, is that the Society for Visiting Scientists must be able to help people visit, and for that it needs some premises. 